\title{
Riser of Dual Fluidized Bed Gasification Reactor: Investigation of Combustion Reactions
}

\author{
Rajan Kumar Thapa Britt M. E. Moldestad \\ Department of Process, Energy and Environmental Technology \\ University College of Southeast Norway, Porsgrunn, Norway \\ Rajan.k.thapa@usn.no
}

\begin{abstract}
The riser of a dual fluidized bed gasification reactor heats bed materials by burning residual char particles coming from gasification part of the reactor. A validated Computational Particle Fluid Dynamic (CPFD) model is applied to simulate combustion of char particles in a riser of dual fluidized bed gasification reactor in a demonstration plant with $8 \mathrm{MW}$ fuel capacity. The plant is located in Güssing, Austria. The three-dimensional model is used investigate combustion reaction as a function of the bottom, primary and secondary air feed rates. The results show there is a still possibility to improve combustion reaction by optimizing air feed rates, which can maximize the bed material temperature without increasing additional char particles feed.
\end{abstract}

Keywords: dual fluidized bed, gasification, biomass, combustion, riser

\section{Introduction}

Biomass gasification is one of the promising technologies for combined heat and power production and synthesis processes leading to the production of liquid biofuels. Biomass has two major advantages: it is carbon dioxide neutral and homogeneously and locally available all over the world (Asadullah, 2014). There are various types of gasification technologies such as fix bed, moving the bed and fluidized bed (Basu, 2013). Dual fluidized bed steam gasification is one of the latest technologies among them (Göransson et al., 2011; Hofbauer et al., 2001).

Steam gasification in a dual fluidized bed reactor is a complex thermochemical process by which biomass is converted to a mixture of combustible and noncombustible gasses and other minor components. The combustible gasses are called producer gas. The major components of the producer gas are carbon monoxide, hydrogen, and methane. The non-combustible gasses are carbon dioxide and water vapor (Hofbauer et al., 1997, 2002a,b). The principle of the dual fluidized bed gasification reactor is shown in Figure 1. The reactor consists of two parts where one is a bubbling fluidized bed gasification reactor, and the other is a circulating fluidized bed combustion reactor. The gasification reactions are endothermic, and heat required for the reactions is supplied by circulating hot bed materials from the combustion reactor (Kern et al., 2013). The bed material can be sand or olivine particles. The primary purpose of the bed material is to transfer heat from the combustion reactor to the gasification reactor. The bed material is heated in the combustion reactor by burning char particles. The char particles, are residual char after the gasification process, which is transported from the gasification reactor to the combustion reactor along with the bed materials.

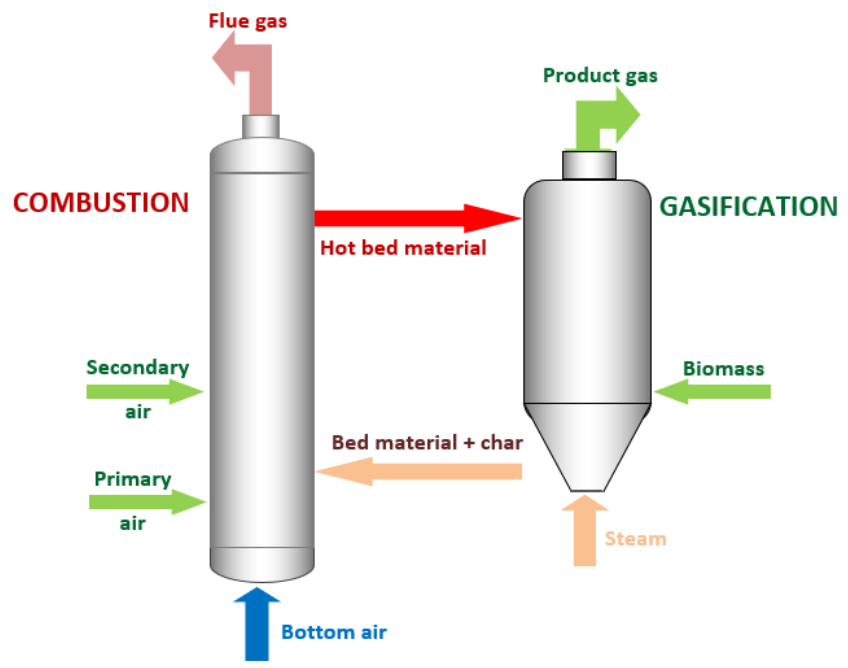

Figure 1. Principle of dual fluidized bed gasification system.

To optimize the performance of the reactor, gas-particle flow and combustion reaction should be optimized. It means that the reactor should have a minimum fluctuation of bed material temperature, steady transport of hot bed material to the gasification reactor and optimum gas flow rates (Snider and Banerjee, 2010). The temperature of bed material depends on the combustion reaction. The combustion reactions are dependent on the amount of oxygen supply. In the combustion reactor, the oxygen for the combustion reaction is provided from the air which is fed to the reactor from three position as the bottom, primary and secondary air.

The temperature of the bed material is self-controlled by the reactor as a whole. If the temperature of circulated bed material is low, the gasification reaction rates 
become slower leaving more unreacted residual char particles to circulate to the combustion reactor. The more char particles circulated to the combustion reactor, the more the temperature of the bed materials is increased and vice versa (Pfeifer et al., 2011; Wang and Chen, 2013). The self-stabilization process requires two essential conditions to be fulfilled. Firstly, the initial temperature of the bed materials should be maintained near to the reaction temperature (about $850^{\circ} \mathrm{C}$ ) which is achieved by burning a part of the producer gas to start up the reactor. Secondly, it is important to maintain constant bed material circulation rate which depends on the air feed rates and air feed positions in the reactor. Previous studies performed by the authors showed that the optimum ratio of bed materials to biomass feed rate was 25-30 for Güssing plant (Thapa and Halvorsen, 2014).

Preheated air is fed to the combustion reactor from the bottom and two positions along the height of the reactor as primary and secondary air. The air supplies necessary oxygen for combustion reaction and simultaneously serves as fluidizing gas to transport heated bed materials to the gasification reactor. The feed air is preheated to achieve better combustion of char in the reactor.

It is not well understood, whether all residual char particles coming from the gasification reactors are totally combusted during the flow along the riser of the combustion reactor. It is because the gas velocity in the combustion reactor is high and the residence time may not be long enough for all char particles to undergo complete combustion. Moreover, the air feed should ensure sufficient oxygen to burn all char particles.

The fluid dynamics of the combustion reactor requires the lower part of the reactor to be in bubbling fluidization regime, which means that the bottom air feed velocity should be lower. If the velocity is very high, a part of flue gas can pass to the gasification reactor making the product gas diluted by nitrogen and carbon dioxide contained in the flue gas, which is undesirable. The middle and upper parts are in the fast fluidization regime (Kaushal et al., 2008a). Moreover, the flow properties in the reactor vary with height because of the three different feed position of the bottom, primary and secondary air. The flow parameters are different at different temperature due to density and viscosity variation of the fluidizing gas.

A three-dimensional CPFD model is developed to study and optimize fluid dynamic properties and reaction kinetics in the combustion reactor. The gas-particle flow is investigated in high-temperature fluid flow with char combustion. The model is simulated using the commercial Computational Particle Fluid Dynamic (CPFD) software Barracuda VR. 15. The effect of char combustion is studied with varying flow rates of the bottom, primary and secondary airflow rates. The aim of the series of simulation is to investigate char combustion in the reactor and flow rates of the bottom, primary and secondary airflow rates. All parameters used in the simulations are based on the combustion riser in the biomass gasification plant in

\section{Güssing, Austria.}

\section{Mathematical Model}

In this work, a Computational Particle Fluid Dynamic (CPFD) model is applied to simulate the gas-solid flow with heat transfer and chemical reactions. The CPFD numerical methodology incorporates multi-phase-particlein-cell (MP-PIC) method (Andrews and O'Rourke, 1996; Snider, 2001). The gas phase is solved using Eulerian grid and the particles are modeled as Lagrangian computational particles. Gas and particle momentum equations are solved in three dimensions. The fluid is described by the Navier-Stokes equation with strong coupling to the discrete particles. The particle momentum follows the MPPIC description which is a Lagrangian description of particle motions described by ordinary differential equations coupling with the fluid (Snider and Banerjee, 2010).

In the CPFD numerical method, actual particles are grouped into computational particles, each containing a number of particles with identical densities, volume and velocities located at a specific position. The computational particle is a numerical approximation similar to the numerical control volume where a spatial region has a single property for the fluid. With these computational particles, large commercial systems containing billions of particles can be simulated using millions of computational particles. This possibility of the CPFD numerical method is used in this work to simulate the riser part of the large scale dual fluidized bed steam gasification plant.

\section{Governing equations}

The volume averaged fluid mass and momentum equations are:

$$
\frac{\partial\left(\varepsilon_{g} \rho_{g} \mathbf{u}_{g}\right)}{\partial t}+\nabla\left(\varepsilon_{g} \rho_{g} \mathbf{u}_{g} \mathbf{u}_{g}\right)=\varepsilon_{g} \nabla p-\mathbf{F}+\varepsilon_{g} \rho_{g} \mathbf{g}+\varepsilon_{g} \tau_{g}
$$

where $\varepsilon_{g}, \rho_{g}$, and $\mathbf{u}_{g}$ are gas volume fraction, density and velocity respectively, $\mathrm{p}$ is gas pressure, $\mathbf{g}$ is the acceleration due to gravity, $\mathbf{F}$ is the rate of momentum exchange per unit volume between the gas and solid phase and $\tau_{g}$ is stress tensor which can be expressed in index notation as:

$$
\tau_{g, i j}=\mu\left(\frac{\partial u_{i}}{\partial x_{j}}+\frac{\partial u_{j}}{\partial x_{i}}\right)-\frac{2}{3} \mu \delta_{i j} \frac{\partial u_{k}}{\partial x_{k}}
$$

where $\mu$ is shear viscosity. The shear viscosity is the sum of laminar shear viscosity and turbulence viscosity based on the Smagorinsky turbulence model. In the model, large eddies are directly calculated. The unresolved sub-grid turbulence is modeled by using eddy viscosity. The turbulence viscosity is given as:

$$
\mu_{t}=C \rho_{g} \Delta^{2} \sqrt{\left(\frac{\partial u_{i}}{\partial x_{j}}+\frac{\partial u_{j}}{\partial x_{i}}\right)^{2}}
$$

where C is sub-grid eddy coefficient and known as Smagorinsky coefficient. 
MP-PIC method calculates the particle phase dynamics using the particle distribution function (PDF), $f_{p}$. A transport equation is solved for the PDF. The transport equation for $f_{p}$ is given by [14] and is expressed as:

$$
\frac{d_{f_{p}}}{d t}+\frac{\partial\left(f_{p} u_{p}\right)}{d x}+\frac{\partial\left(f_{p} A_{p}\right)}{d u}=\frac{f_{D}-f_{p}}{\tau_{D}}
$$

where $u_{p}$ is particle velocity, $f_{D}$ is the particle distribution function for the local mass averaged particle velocity and $\tau_{D}$ is the collision damping time. $A_{p}$ is the particle acceleration which is given by:

$A_{p}=\frac{\partial u_{p}}{d t}=D_{p}\left(u_{g}-u_{p}\right)-\frac{1}{\rho_{p}} \nabla p_{g}+g-\frac{1}{\varepsilon_{p} \rho_{p}} \nabla \tau_{g}+g+F_{p}$

In the equation above, $\varepsilon_{p}$ is particle volume fraction, $\rho_{p}$ is particle density, $p_{g}$ is gas pressure, $\tau_{p}$ is contact normal stress. More details about the $\tau_{p}$ can be found in (O'Rourke and Snider, 2010). $F_{p}$ is the particle friction per unit mass, related to the relative particle motion and becomes important at very low particle flow at near closed packed bed (Snider, 2007) and $D_{p}$ is the drag function. The Wen-Yu drag model is implemented in this work (Wen, 1966).

$$
D_{p}=C_{D} \frac{3}{8} \frac{\rho_{g}}{\rho_{p}} \frac{\left|u_{g}-u_{p}\right| \varepsilon_{g}^{-2.65}}{r_{p}}
$$

where

$$
\begin{gathered}
D_{p}=C_{D} \begin{cases}\frac{24}{R e}\left(1+0.15 R e^{0.678}\right), & R e<1000 \\
0.44, & R e \geq 1000\end{cases} \\
R e=\rho_{g} \frac{\left|u_{g}-u_{p}\right| r_{p}}{\mu_{g}} \text { and } r_{p}=\left(\frac{m}{\frac{4}{3} \pi \rho_{p}}\right)^{\left(\frac{1}{3}\right)}
\end{gathered}
$$

\section{Model Parameters and Geometry}

The dimensions of the reactor are the same as the combustion reactor in the biomass gasification plant in Güssing, Austria. The basic dimensions of the combustion part of the reactor are shown in Table 1.

Table 1. Reactor Dimensions.

\begin{tabular}{lcc}
\hline Dimensions & Units & Value \\
\hline Diameter & $\mathrm{m}$ & 0.66 \\
Height & $\mathrm{m}$ & 12 \\
Primary air inlet & $\mathrm{m}$ & 1.5 \\
Secondary air inlet & $\mathrm{m}$ & 3.5 \\
\hline
\end{tabular}

In the plant, the gasification and combustion occur simultaneously in the bubbling fluidized bed gasification reactor and in circulating fluidized bed combustion reactor. The whole reactor is a combination of these two. However, the aim of current study is only the combustion part of the reactor. Therefore, the combustion part of the reactor is separated in the model replacing circulation of the bed materials by the inlet and outlet boundaries. Dotted lines in Figure 2 show the control volume of model geometry.

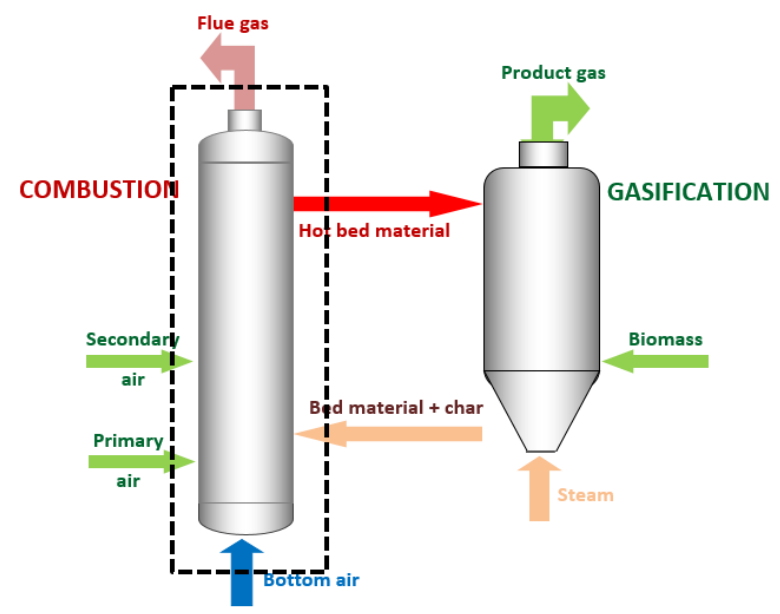

Figure 2. Control volume of model geometry.

In the CPFD computational model, grid generating and solving flow and reactions in a rectangular geometry is better than in a circular geometry. For this reason, the circular diameter of the geometry is converted into rectangular with the equivalent cross-sectional area. The geometry used in the CPFD model with all boundary conditions and grids are shown in Figure 3.

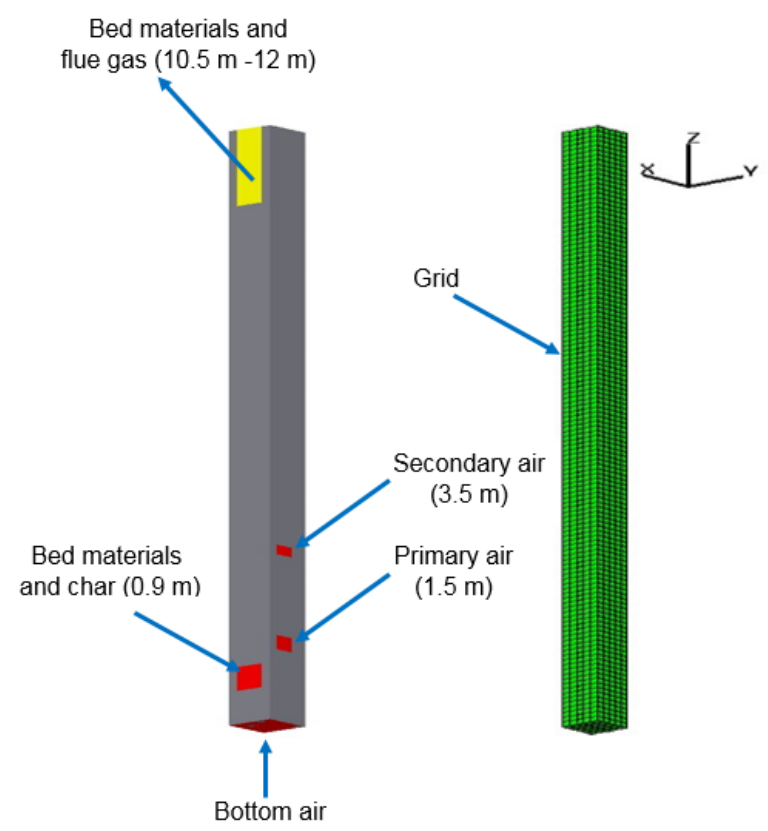

Figure 3. Grid and boundary conditions of the riser.

The combustion reactor uses air as a fluidizing agent as well as an oxidizing agent. The gas-particle flow involves a complex mixture of air, flue gas, olivine particles 
and char. The properties of gas and particles used in the simulation are given in Table 2.

Table 2. Properties of Solids and Gases.

\begin{tabular}{lcc}
\hline Properties & Units & Value \\
\hline Olivine particle size & $\mu \mathrm{m}$ & $200-800$ \\
Olivine density & $\mathrm{kg} / \mathrm{m}^{3}$ & 2960 \\
Char particles size & $\mathrm{mm}$ & $1-5$ \\
Char density & $\mathrm{kg} / \mathrm{m}^{3}$ & 200 \\
Air density & $\mathrm{kg} / \mathrm{m}^{3}$ & $0.27-1.06$ \\
Air temperature inlet & $\mathrm{K}$ & $333-1300$ \\
Air viscosity & $\mathrm{Pa} \cdot \mathrm{s}$ & {$[1.98-4.9] \cdot 10^{-5}$} \\
\hline
\end{tabular}

In the combustion reactor, olivine particles and char have a wide range of size distribution. The size distribution of char and bed materials are presented in Figure 4(a) and 4(b) respectively.

The particle sizes expressed in the figure are the radius of particles. It is because Barracuda uses radius to represent particle size. The combustion reactions and their reaction kinetics involved in the CPFD model is given in Table 3 (Kaushal et al., 2008a).

Chemical reactions can affect gas flow rates, gas compositions, particle sizes and particle densities. The reactions, on the other hand, can be affected by temperature, gas-particle mixing and gas feed positions and feed rates in the reactor. There is strong interdependence between reaction chemistry and particle-fluid dynamics. Therefore, it is important to take into account the change in flow behavior due to the combustion reaction in the riser.

The volume average chemistry is used in the current model. The gas volume of each cell in the grid acts as control volume for the reaction calculations. In volume average chemistry, each control volume is the gas volume in a cell. The reactions are written in stoichiometric form. Temperature, pressure and solid dependence are entered as rate coefficients.

The particle dependency term is the radius of the particle. The temperature is the average temperature of the particle and the bulk fluid.

It is assumed that the particle temperature is constant within the particle.

\section{Results and Discussions}

To simulate the riser of the Güssing plant and to investigate the combustion reaction, the first series of simulations were run with the gas and fuel feed parameters as reported from the biomass gasification plant in Güssing (Kaushal et al., 2008a). The parameters are presented in Table 4.

The table shows the flow rate of the bottom, primary and secondary air with different temperatures. The reason for feeding the air at various position and temperatures is to control the combustion process and bed material circulation rate. The mixture of bed materials and residual char is fed to the combustion reactor at a temperature of 1073
$\mathrm{K}$. The char is combusted in the reactor and it gradually heats the bed materials while moving up along the height of the riser. Therefore, the particle temperature is gradually increased as they move towards the top of the reactor. The temperature of the gas and particles are measured from the bottom and every one-meter height of the reactor. The simulated fluid and particle temperature along the height of the reactor is shown in Figure 5.

The figure indicates that the fluid and particle temperature are changing with height in the riser. At every position in the reactor, the fluid temperature is higher than particle temperature. It indicates that the heat transfer between particles and fluid is not sufficient due to high velocity and low residence time. The fluid temperature deviates sharply from particle temperature above the height of $2 \mathrm{~m}$. This point is just above the primary air feed point. Preheated primary air significantly improves the char combustion process in the reactor and increases the temperature. However, after about $8 \mathrm{~m}$ height, the fluid and particle temperature do not increase indicating that char combustion does not occur above this height of the bed.

The char particle volume fraction and the mole fraction of the major components of the flue gas is presented in Figure 6. The figure shows that the residual char particles fed to the combustion reactor are not completely burned. The existence of the small amount of char particles at the top of the reactor suggests that the char particles are recirculated back to the gasification reactor. As expected, the mole fraction of $\mathrm{CO}_{2}$ increasing from the bottom to the top while the oxygen mole fraction is decreasing. The oxygen mole fraction is almost zero at a height about $7 \mathrm{~m}$ implying that there is an insufficient amount of oxygen to obtain total combustion of char particles. The small amount of $\mathrm{H} 2$ at the top of reactor makes that fact clearer.

The $C O$ concentration is a strong function of the available oxygen. Hence, the primary air flow which is the biggest among the all air flow rates influences the $C O$ concentration most (Kaushal et al., 2008b).

A series of simulation were run by gradually increasing the bottom airflow rate. The results are presented in Figure 7.

An increasing amount of bottom air increases the gas and particle temperature. The maximum particle temperature is increased from about $1150 \mathrm{~K}$ to about $1220 \mathrm{~K}$ in the first series of simulations (Figure 5). The increase in temperature without increasing the mass flow rate of the char particles indicates that not all the char particles are burned. In other words, there is still some uncombusted char particles passing through the combustion reactor to the gasification reactor. However, increasing the bottom air increases the fluid temperature much more than the particle temperature. It may be due to decreased residence time for the particles in the combustion reactor. Increased bottom air flow rate increases the fluidization velocity making particles be transported faster. In addition, the high feed rate of bottom air is not desirable due to the risk of flue gas leakage to the gasification reactor. 


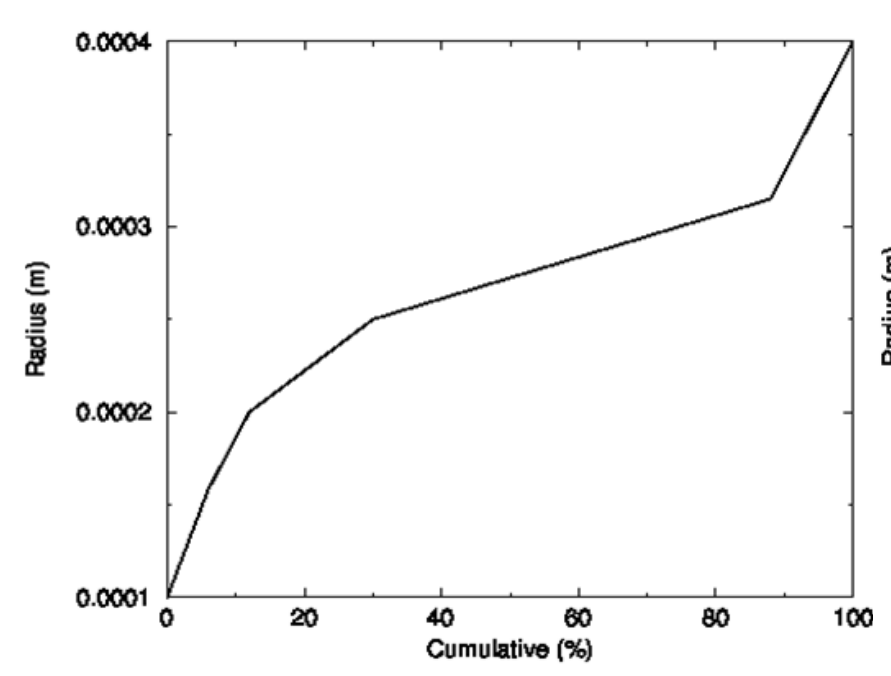

(a)

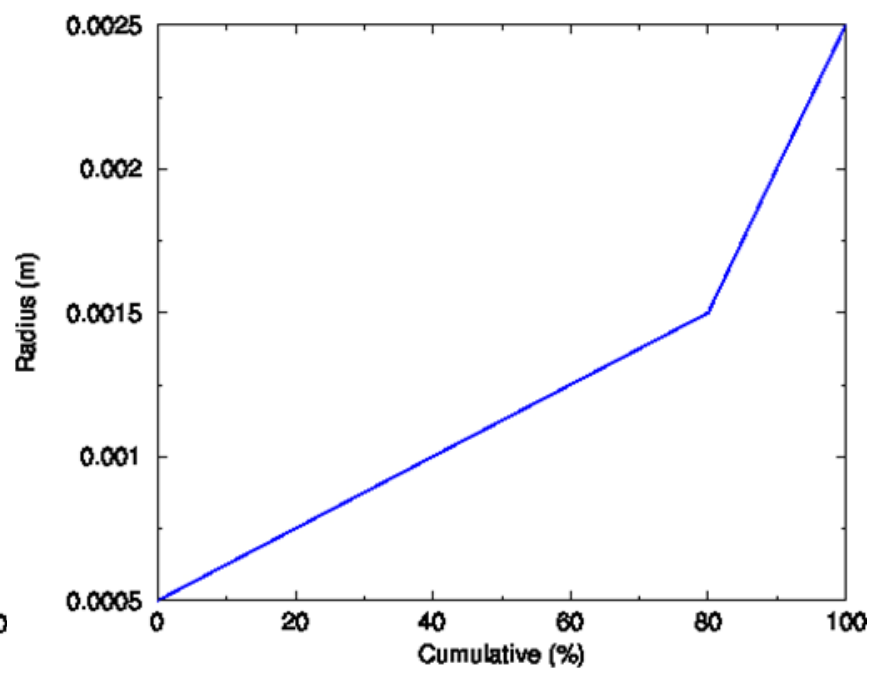

(b)

Figure 4. Particle size distribution (a) Olivine (b) Char.

Table 3. Reactions and Reaction Kinetics.

\begin{tabular}{lll}
\hline Reactions & Reaction Rate & $K_{1}$ \\
\hline $\mathrm{C}+\mathrm{O}_{2}=\mathrm{CO}+\mathrm{CO}_{2}$ & $R_{1}=\mathrm{K}_{1}\left[\mathrm{O}_{2}\right]^{0.5}$ & $8.56 \cdot 10^{-2} \exp \left(\frac{-2237}{\mathrm{~T}}\right)$ \\
$\mathrm{C}+\mathrm{H}_{2} \mathrm{O}=\mathrm{CO}+\mathrm{H}_{2}$ & $R_{2}=\mathrm{K}_{1}\left[\mathrm{H}_{2} \mathrm{O}\right]^{0.57}$ & $2.62 \cdot 10^{8} \exp \left(\frac{-23000}{T}\right)$ \\
$\mathrm{H}_{2}+\frac{1}{2} \mathrm{O}_{2}=\mathrm{H}_{2} \mathrm{O}$ & $R_{3}=K_{1}\left[\mathrm{H}_{2}\right]^{1.5}\left[\mathrm{O}_{2}\right]$ & $1.63 \cdot 10^{9} T^{3 / 2} \exp \left(\frac{-3420}{T}\right)$ \\
$\mathrm{CO}+\frac{1}{2} \mathrm{O}_{2}=\mathrm{CO}_{2}$ & $R_{4}=\mathrm{K}_{1}\left[\mathrm{H}_{2}\right]^{1.5}\left[\mathrm{O}_{2}\right]^{0.5}\left[\mathrm{H}_{2} \mathrm{O}\right]^{0.5}$ & $3.25 \cdot 10^{7} \exp \left(\frac{-15098}{\mathrm{~T}}\right)$ \\
$\mathrm{CO}+\mathrm{H}_{2} \mathrm{O}=\mathrm{H}_{2}+\mathrm{CO}_{2}$ & $R_{5}=\mathrm{K}_{1}[\mathrm{CO}]\left[\mathrm{H}_{2} \mathrm{O}\right]$ & $0.03 \exp \left(\frac{-7249}{T}\right)^{T}$ \\
\hline
\end{tabular}

Table 4. Flow Parameters - Gussing Plant.

\begin{tabular}{llc}
\hline Parameters & $\begin{array}{l}\text { Feed Rate } \\
{\left[\mathrm{Nm}^{3} / \mathrm{h}\right]}\end{array}$ & Temperature $[\mathrm{K}]$ \\
\hline Bottom air & 720 & 333 \\
Primary air & 2880 & 673 \\
Secondary air & 869 & 860 \\
Bed materials & $37[\mathrm{~kg} / \mathrm{s}]$ & - \\
\hline
\end{tabular}

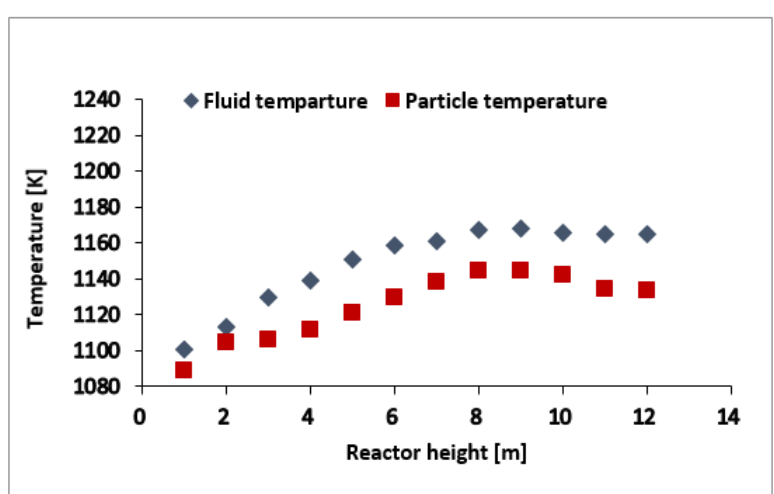

Figure 5. Fluid and particle temperature along the height of the reactor.

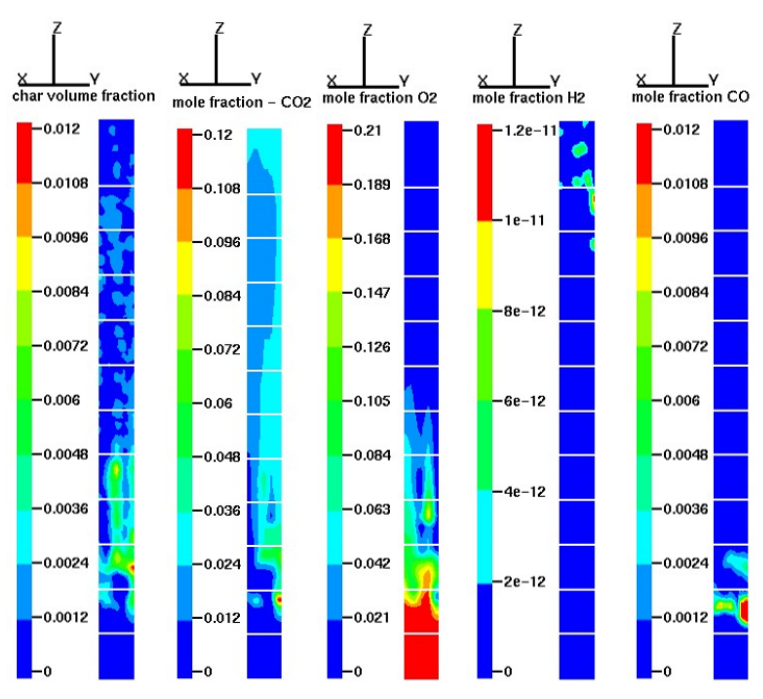

Figure 6. Particles and gas fractions.

A series of simulations were run to investigate the change in fluid-particle temperature with increasing primary air flow rate. The results presented in Figure 8 shows that the particle temperature is again increasing with the increasing primary air flow rate. Moreover, the difference between the fluid and particle temperature is also de- 


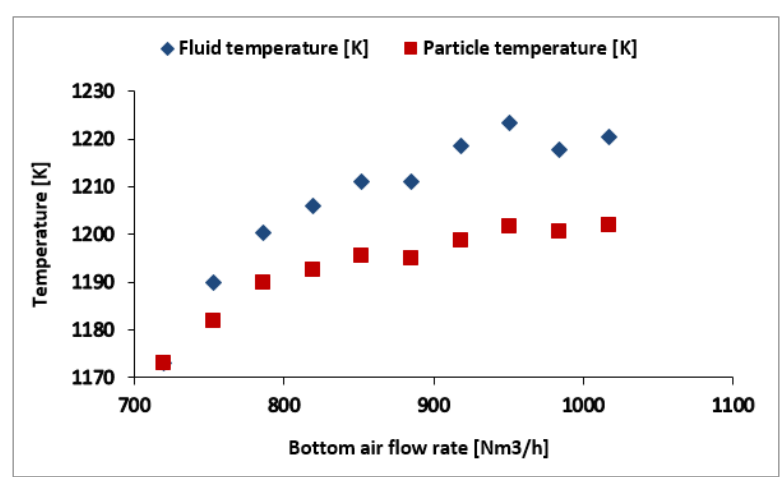

Figure 7. Fluid and particle temperature at a height of $10 \mathrm{~m}$ with increasing bottom air flow rate.

creased in this case.

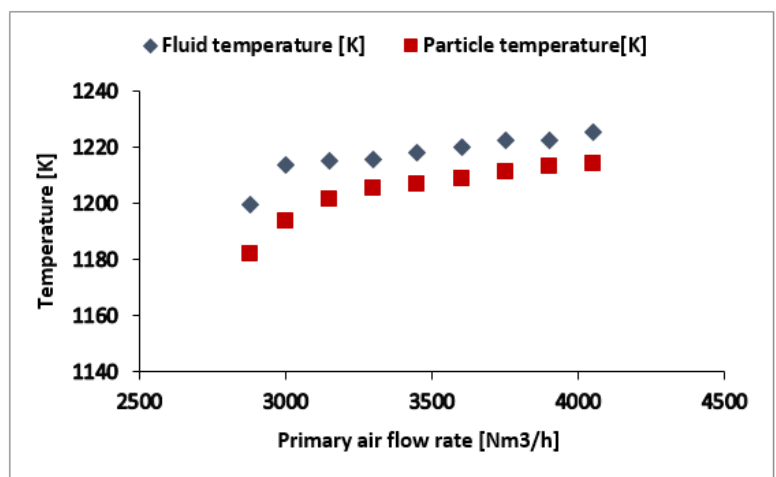

Figure 8. Fluid-particle temperature with increasing primary air flow rate.

The results of the simulation series with increasing secondary air flow rate also show that there is a significant change in fluid-particle temperature as shown in Figure 9.

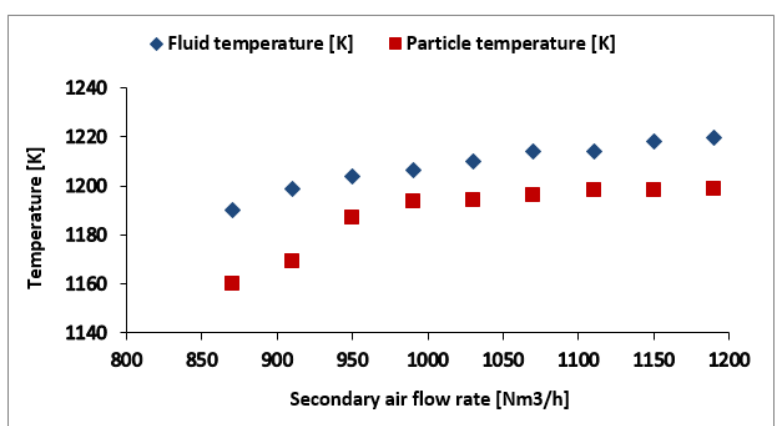

Figure 9. Fluid particle temperature with increasing secondary air flow rate.

The overall particle temperature distribution along the combustion reactor is presented in Figure 10.

The particle temperature distribution at increasing air flow rates of the bottom, primary and secondary air are compared with the particle temperature at the air flow rate used at the Güssing plant. The results show that increasing primary and secondary air flow rates result in higher and more uniform particle temperature distribution in the

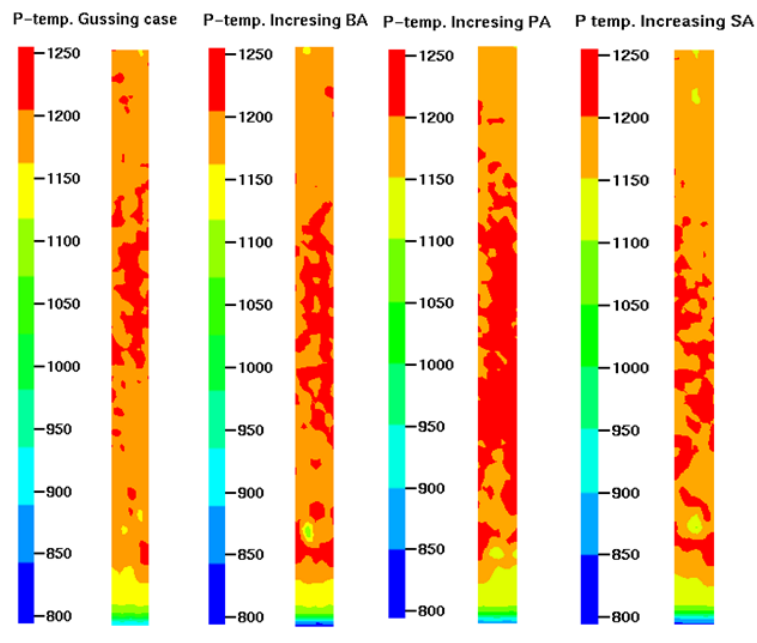

Figure 10. Snapshot of particle temperature distribution along the combustion reactor at 400 s of simulation time.

reactor.

\section{Conclusions}

A 3D CPFD model is developed to investigate the effect of bottom, primary and secondary air flow rates in the combustion process and bed material temperature in the riser of a dual fluidized bed biomass gasification reactor. The simulated reactor is located at $8 \mathrm{MW}$ fuel, biomass gasification plant in Güssing, Austria. Series of simulations were run using commercial CPFD software Barracuda V15. The first series of simulation were performed with all parameters as in the Güssing plant. The results show that some un-combusted char particles are passing through the reactor. Three series of simulations carried out with increasing bottom, primary and secondary air feed rate. All the cases show increasing temperature with increasing air feed rates at a constant feed rate of char particles. The results of the simulations also indicate that increase in primary air flow rate results in the highest particle temperature with more uniform temperature distribution along the reactor than the cases with increasing bottom and secondary air feed rate. The results show that there is still a possibility for optimization of air flow rates for combustion reaction in the riser.

\section{References}

Michael J. Andrews and Peter J. O'Rourke. The multiphase particle-in-cell (MP-PIC) method for dense particulate flows. International Journal of Multiphase Flow, 22(2):379-402, 1996. doi:10.1016/ 0301-9322(95)00072-0.

Mohammad Asadullah. Barriers of commercial power generation using biomass gasification gas: a review. $R \boldsymbol{e}$ newable and Sustainable Energy Reviews, 29:201-215, 2014. doi:10.1016/j.rser.2013.08.074.

Prabir Basu. Biomass gasification, pyrolysis and torrefac- 
tion: practical design and theory. Academic press, 2013.

Kristina Göransson, Ulf Söderlind, Jie He, and Wennan Zhang. Review of syngas production via biomass DFBGs. Renewable and Sustainable Energy Reviews, 15 (1):482-492, 2011. doi:10.1016/j.rser.2010.09.032.

Hermann Hofbauer, Rauch Reinhard, Bosch Klaus, Koch Reinhard, and Aichernig Christian. Biomass CHP plant güssing-a success story. Available online: http://members. aon. at/biomasse/strassbourg. pdf (accessed on 14 December 2016), 2001.

Hermann Hofbauer, Rauch Reinhard, Bosch Klaus, Koch Reinhard, and Aichernig Christian. Biomass CHP plant güssing-a success story. Expert Meeting on Pyrolysis and Gasification of Biomass and Waste, Strasbourg, France, 2002b.

Hermann Hofbauer, Reinhard Rauch, Gerhard Löffler, Sebastian Kaiser, E Fercher and H Tremmel. Six years experience with the FICFB-gasification process. 12th European Conference and Technology Exhibition on Biomass, Energy, Industry and Climate Protection, Amsterdam, 2002a.

Hermann Hofbauer, Günter Veronik, Thomas Fleck, Reinhard Rauch, Herbert Mackinger, and Erich Fercher. The FICFB-gasification process. Springer, 1997. doi:10.1007/978-94-009-1559-682.

Priyanka Kaushal, Tobias Pröll, and Hermann Hofbauer. Model for biomass char combustion in the riser of a dual fluidized bed gasification unit: Part i model development and sensitivity analysis. Fuel Processing Technology, 89(7):651-659, $2008 \mathrm{a}$. doi:10.1016/j.fuproc.2007.12.010.

Priyanka Kaushal, Tobias Pröll, and Hermann Hofbauer. Model for biomass char combustion in the riser of a dual fluidized bed gasification unit: Part ii model validation and parameter variation. Fuel Processing Technology, 89(7):660-666, 2008b. doi:10.1016/j.fuproc.2007.12.009.

Stefan Kern, Christoph Pfeifer, and Hermann Hofbauer. Gasification of lignite in a dual fluidized bed gasifierinfluence of bed material particle size and the amount of steam. Fuel processing technology, 111:1-13, 2013. doi:10.1016/j.fuproc.2013.01.014.

Peter J. O'Rourke and Dale M. Snider. An improved collision damping time for MP-PIC calculations of dense particle flows with applications to polydisperse sed-imenting beds and colliding particle jets. Chemical Engineering Science, 65(22):6014-6028, 2010. doi:10.1016/ j.ces.2010.08.032.

DOI: $10.3384 /$ ecp 1714292
Proceedings of the 9th EUROSIM \& the 57th SIMS September 12th-16th, 2016, Oulu, Finland
Koppatz, and Hermann Hofbauer. Steam gasification of various feedstocks at a dual fluidised bed gasifier: Impacts of operation conditions and bed materials. Biomass Conversion and Biorefinery, 1(1):39-53, 2011. doi:doi:10.1007/s13399-0110007-1.

Dale M. Snider. An incompressible three-dimensional multiphase particle-in-cell model for dense particle flows. Journal of Computational Physics, 170(2):523549, 2001. doi:10.1006/jcph.2001.6747.

Dale M. Snider. Three fundamental granular flow experiments and CPFD predictions. Powder Technology, 176 (1):36-46, 2007. doi:10.1016/j.powtec.2007.01.032.

Dale M. Snider and Sibashis Banerjee. Heterogeneous gas chemistry in the cpfd eulerianlagrangian numerical scheme (ozone decomposition). Powder Technology, 199(1):100-106, 2010. doi:10.1016/j.powtec.2009.04.023.

Rajan K. Thapa and Britt M. Halvorsen. Heat transfer optimization in a fluidized bed biomass gasification reactor. Heat Transfer XIII: Simulation and Experiments in Heat and Mass Transfer, 83:169, 2014.

Li-Qun Wang and Zhao-Sheng Chen. Gas generation by co-gasification of biomass and coal in an autothermal fluidized bed gasifier. Applied Thermal Engineering, 59(1):278-282, 2013. doi:10.1016/j.applthermaleng.2013.05.042.

Wen C. Yu. Mechanics of fluidization. In The Chemical Engineering Progress Symposium Series, volume 6, pages 100-101, 1966. 